\title{
The impact of socioeconomic conditions, social networks, and health on frail older people's life satisfaction: a cross-sectional study
}

\author{
Helene Berglund, ${ }^{1-3}$ Henna Hasson, ${ }^{3-5}$ Katarina Wilhelmson, ${ }^{2,3,6}$ Anna Dunér, ${ }^{3,7}$ Synneve \\ Dahlin-Ivanoff 2,3
}

${ }^{1}$ Institute of Health and Care Sciences, The Sahlgrenska Academy at University of Gothenburg;

${ }^{2}$ Center of Aging and Health - AGECAP, Section of Health and Rehabilitation, University of Gothenburg; ${ }^{3}$ Vårdalinstitutet, Swedish Institute for Health Sciences, Lund; ${ }^{4}$ Department of Learning, Informatics, Management and Ethics, Karolinska Institutet, Medical Management Centre (MMC), Stockholm; ${ }^{5}$ Centre for Epidemiology and Community Medicine, Stockholm County Council, Stockholm; ' ${ }^{6}$ Department of Geriatrics, Sahlgrenska University Hospital, Gothenburg; ${ }^{7}$ Department of Social Work, University of Gothenburg, Sweden

\begin{abstract}
It has been shown that frailty is associated with low levels of wellbeing and life satisfaction. Further exploration is needed, however, to better understand which components constitute life satisfaction for frail older people and how satisfaction is related to other life circumstances. The aim of this study was to examine relationships between frail older people's life satisfaction and their socioeconomic condi-
\end{abstract}

Correspondence: Helene Berglund, Institute of Health and Care Sciences, The Sahlgrenska Academy at University of Gothenburg, P.0 Box 457, 40530 Gothenburg, Sweden.

Tel.:+46.317.866107.

E-mail: helene.berglund@gu.se

Key words: Frail older people, life satisfaction, cross-sectional study, logistic regression analysis.

Acknowledgements: the work reported here was supported by grants from Vårdalinstitutet, The Swedish Institute for Health Sciences and AgeCap, the Centre for Ageing and Health at the University of Gothenburg. The involvement of the second author was funded by ERA-AGE2, Future Leaders of Ageing Research in Europe (FLARE)/Swedish Council for Working Life and Social Research. Special thanks to Anna Lindgren PhD at the Centre for Mathematical Sciences, Lund University for statistical advice. The authors are particularly grateful to the older people who participated in the study.

Contributions: HB, conception and design, collection of data, analysis and interpretation of data, drafting, final approval; $\mathrm{HH}, \mathrm{KW}, \mathrm{AD}$, and $\mathrm{SD}$, conception and design, critical revision, final approval.

Conflicts of interest: the authors declare no potential conflict of interests.

Received for publication: 11 0ctober 2015 .

Revision received: 19 March 2016.

Accepted for publication: 27 April 2016.

This work is licensed under a Creative Commons AttributionNonCommercial 4.0 International License (CC BY-NC 4.0).

(C) Copyright H. Berglund et al., 2016

Licensee PAGEPress, Italy

Health Psychology Research 2016; 4:5578

doi:10.4081/hpr.2016.5578 tions, social networks, and health-related conditions. A cross-sectional study was conducted $(\mathrm{n}=179)$. A logistic regression analysis was performed, including life satisfaction as the dependent variable and 12 items as independent variables. Four of the independent variables made statistically significant contributions: financial situation (OR 3.53 ), social contacts (OR 2.44), risk of depression (OR 2.26), and selfrated health (OR 2.79). This study demonstrates that financial situation, self-rated health conditions and social networks are important components for frail older people's life satisfaction. Health and social care professionals and policy makers should consider this knowledge in the care and service for frail older people; and actions that benefit life satisfaction - such as social support - should be promoted.

\section{Introduction}

Life satisfaction is a fundamental part of older people's well-being. Older people, who are frail often have multiple chronic conditions and impairments and are particularly vulnerable (Fried, Ferrucci, Darer, Williamson, \& Anderson, 2004). It has been shown that frailty is associated with low levels of well-being and life satisfaction (Andrew, Fisk, Rockwood, 2012; Strawbridge, Shema, Balfour, Higby, \& Kaplan, 1998). However, it is of importance to further explore what constitutes life satisfaction for frail older people and how satisfaction is related to other life circumstances, such as socioeconomic conditions, social networks, and health-related conditions. Health and social care professionals should then consider these relationships and knowledge of life satisfaction in the care and service of frail older people.

There are several theoretical concepts associated with life satisfaction, including subjective well-being and quality of life. Subjective well-being is suggested to include individuals' moods, emotions, and cognitive evaluations of life satisfaction (Diener, Suh, Lucas, \& Smith, 1999). Quality of life, however, has tended to indicate an overall concept involving global as well as domain-specific life satisfaction (Sirgy, 2012). Accordingly, life satisfaction can be seen as a sub-theme to subjective well-being and quality of life. Satisfaction with life as a whole has further been equated with happiness (Fugl-Meyer, Bränholm, \& Fugl-Meyer, 1991); it is a useful measurement concept where instruments measuring quality of life are weak (Borg, Berg, Fugl-Meyer, \& Larsson, 2010), such as in the social aspects of life.

Life satisfaction appears to be influenced by socioeconomic conditions, social networks (Diener et al., 1999; Pinquart, \& Sörensen, 
2000) and health-related conditions (Easterlin, 2003). In addition, personality and personal aspirations in life have been shown to influence life satisfaction (Campbell, Converse, \& Rodgers, 1976). Gender seems to have limited influence on life satisfaction (Diener et al., 1999). When differences have been observed, women usually report higher life satisfaction (Diener et al., 1999; White, 1992). However, gender differences appear to be influenced by other variables, such as age. Shmotkin (1990) concluded that younger women reported higher life satisfaction than younger men, and older women (aged $\geq 60$ years) reported lower life satisfaction than older men. Further, it has been shown that married persons, or persons living with a partner, are happier than persons living alone.

Small correlations between life satisfaction and education have also been found, but it appears that one's financial situation is more indicative of life satisfaction than is one's education (Diener et al., 1999).

In a study by Berg, Hoffman, Hassing, McClearn, and Johansson (2009), it was shown that satisfaction with one's financial situation was associated with greater life satisfaction among older people (aged 280). In contrast, Abu-Bader, Rogers and Barusch (2003) found no association between financial situation and life satisfaction among frail older people.

Studies addressing the relation between life satisfaction and age have resulted in ambiguous findings. Diener, Suh, Lucas, and Smith (1999) and Hamarat et al. (2002) have reported that life satisfaction is stable throughout life, while others have reported a positive correlation between age and life satisfaction (Horley \& Lavery, 1995; Prenda \& Lachman, 2001). Still other investigators have found decreases in life satisfaction levels with older age (Berg et al., 2009; Mroczek, \& Spiro, 2005).

While medically based measures of health have not been as extensively investigated as self-rated health in relation to life satisfaction, Berg, Hassing, Nilsson, and Johansson (2009) have reported a weak relationship between medically based measures of health and life satisfaction among older people (aged $\geq 80$ ). Independence in activities of daily living (ADL) has been shown to be of special importance for the very elderly (aged $\geq 85$ ) (Bowling, Farquhar, Grundy, \& Formby, 1993; Hillerås, Jorm, Herlitz \& Winblad, 2001). A decrease in functional capacity particularly influences one's psychological health. Bowling and Grundy (1997) showed that decreases in ADL scores were associated with worry and depression, especially among older people aged $\geq 85$ years. Further, feeling worried was significantly related to low life satisfaction among older people (aged $\geq 65$ ) with reduced functional capacity (Borg et al., 2008).

Frailty is closely related to multiple chronic conditions and disability. It can be defined as increased vulnerability to stressors due to decreased physiologic reserves (Fried et al., 2004) and decreased psychological and social functioning (Gobbens, Luijkx, Wijnen-Sponselee $\&$ Schols, 2010). Frailty has been shown to be more important than old age, concerning a negative relationship to life satisfaction (Wilhelmson, Fritzell, Eklund \& Dahlin-Ivanoff, 2013); a strong correlation exists between self-rated health and life satisfaction among frail older people (Abu-Bader et al., 2003; Hillerås et al., 2001).

Previous life satisfaction studies on frail older people appear to lack measures of gender, education, living with a partner, and social networking. Accordingly, there is need for additional research addressing life satisfaction among frail older people - especially within the contexts of socioeconomic conditions and social networks. The aim of this study was to examine relationships between frail older people's life satisfaction and their socioeconomic conditions, social networks, and health-related conditions.

\section{Materials and Methods}

\section{Sample}

This cross-sectional study included data from two research projects. The projects entitled, Continuum of Care for Frail Elderly People (Wilhelmson et al., 2011) and Elderly Persons in the Risk Zone (DahlinIvanoff et al., 2010) were conducted in a middle-sized community and in two urban districts in a major city in Sweden. The middle-sized community and the urban districts include different areas, where people live in their self-owned houses or in rental apartments. The educational level and the income level is slightly better than in the country. Inclusion criteria were older people living in their own homes, aged 80 and older or those aged 65-79 with a need for assistance in at least one activity of daily living (ADL) and with a minimum of one chronic illness. In Sweden, older people keep on living in their own homes, even when they become frail and have complex needs and the current policy is that older people should be able to live independently, managing with formal and informal care as long as possible. Elderly care is a tax-funded service available to all citizens in need (Szebehely \& Trydegård, 2012). Older people with cognitive impairment were not included in the projects. For details about enrollment and allocation, see Wilhelmson et al. (2011) and Dahlin-Ivanoff et al. (2010).

In the projects 161 individuals from the Continuum of Care for Frail Elderly People and 459 from the Elderly Persons in the Risk Zone were included. The projects involved baseline measurements and several follow-ups. The current study involved exclusively the baseline data in both projects, which were collected between 2008 and 2010.

As we intended to include only frail older people in this study, we selected those individuals who fulfilled the criteria for being frail. Frailty was measured using seven frailty indicators: weakness, fatigue, weight loss, reduced physical activity, impaired balance, reduced gait speed, and visual impairment. If a participant fulfilled three or more frailty indicators, we categorized him or her as being frail (DahlinIvanoff et al., 2010; Fried et al., 2004; Wilhelmson et al., 2011). A total of 198 participants from both project samples fulfilled the criteria for being frail.

Both projects were approved by the Regional Ethical Review Board in Gothenburg (413-08 and 650-07) and were registered at Clinical Trials Gov (NCT01260493 and NCT00877058).

\section{Data collection}

Both projects used the same questionnaire, containing several validated scales and items. Questions were asked in face-to-face interviews by $\mathrm{PhD}$ students and project assistants. All interviewers had had previous experience with elderly care and were well trained in interviewing according to the standard guidelines used for obtaining the various measurements in this study. The interviews took place in the older people's homes. The items and the response alternatives were read to the older people and additionally shown on a paper, when needed. The project managers organized regular meetings with all interviewers for ensuring accurate and consistent understanding about the meaning of questionnaire items.

\section{Dependent variable: life satisfaction}

The validated LiSat-11 scale was used to measure older people's life satisfaction (Borg et al., 2010; Fugl-Meyer et al., 1991). It contains eleven items, assessing satisfaction with life as a whole as well as satisfaction with work, financial situation, leisure, friends and acquaintances, sexual life, functional capacity, family life, partner relationship, physical health, and psychological health. Only the global item on satisfaction with life as a whole was used in this study as a dependent 
variable. The LiSat-11 scale has been validated in a representative sample of men and women aged 18-74 years in Sweden. The global item life as a whole has been shown to correlate to all other items (Borg et al., 2010), and it has adequate specificity and discriminate validities as well as test-retest reliability (Fugl-Meyer et al., 1991). The scale is also applicable to older people (aged $\geq 80$ ), as has been demonstrated by Wilhelmson et al. (2013).

Each item has six response alternatives: 1 - very dissatisfied, 2 dissatisfied, 3 - rather dissatisfied, 4 - rather satisfied, 5 - satisfied, and 6 - very satisfied. This present study followed the recommendation that the instrument response alternatives be dichotomized into either not being satisfied (grades 1-4) or being satisfied (grades >4) (Borg et al., 2010; Fugl-Meyer et al., 1991). Missing values at baseline were replaced with the values of the respective outcome for that respondent at the next follow-up, which was carried out three months after baseline (Engels, \& Diehr, 2003). This corrective step was performed in eight cases.

\section{Independent variables}

The following independent variables were selected, based on prior literature: i) socioeconomic conditions: age, gender, cohabitant/living alone, education, and financial situation; ii) social networks: contact with children and other social contacts; iii) health-related conditions: self-rated health, illness, independence in I-ADL (instrumental activities of daily living), independence in P-ADL (personal activities of daily living), and risk of depression.

For education, there were six response alternatives: elementary school, secondary school, high school, community college, incomplete university studies, and university exam. The latter three alternatives were merged into Academic education and the first three were merged into Non-academic education. The item concerning financial situation asked if the participant would be able to obtain 12,000 Swedish Kronor (approximately £1000) within one week, in an emergency situation. The response alternatives were Yes or $\mathrm{No}$, indicating either a Good or Poor financial situation.

Contact with children concerned how often participants met or had other contact (telephone, letter, or e-mail) with their child/children. The response alternatives included: every day, once or several times a week, once or several times a month, once or several times a quarter, once or twice per year, more seldom, and never. These response alternatives were dichotomized to Often (the first two alternatives) and $N o t$ often (the latter five alternatives). If the participant had no children, the latter response alternative was assigned. The item on other social contacts involved the frequency of contact with relatives (other than child/children), friends, and acquaintances. The response alternatives and the dichotomization were the same as in the previous item.

For self-rated health, we used one of the statements in the 36-Item Short Form Health Survey (SF-36) (Majernikova et al., 2012; Ware \& Sherbourne, 1992). The statement was, In general, you would say your health is, and was followed by five response alternatives: excellent, very good, good, fair, and poor. The response alternatives were dichotomized into Good (the first three alternatives) and Poor (the latter two alternatives).

Illness was measured with the Cumulative Illness Rating Scale for Geriatrics (CIRS-G) (Linn, Linn \& Gurel, 1968; Miller et al., 1992), a quantitative rating instrument of the chronic medical illness burden modified for geriatric assessment. CIRS-G contains 14 categories: heart; vascular; hematopoietic; respiratory; eyes, ears, nose, throat, and larynx; upper gastrointestinal; lower gastrointestinal; liver; renal; genitourinary; musculoskeletal; neurological; endocrine; and psychiatric illness. The rating reflects both degree of morbidity and disability. The scale ranges from 0 to 4 , with 0 indicating no problem; 1 , a current mild problem or past significant problem; 2 , a moderate disability or morbidity requiring first line therapy; 3 , a severe or constant significant disability or uncontrollable chronic problems; 4, end-organ failure or severe organ function impairment requiring extremely severe or immediate treatment. In this study, the amount of ratings 2 (moderate disability) were summarized for each person. Illness was dichotomized into $\leq 2$, moderate disabilities and $\geq 3$, moderate disabilities.

Instrumental and personal activities of daily living (I and P-ADL) was measured with Sonn's ADL staircase (Sonn, Grimby \& Svanborg, 1996). The scale was used to measure independence in bathing, dressing, going to the toilet, transferring, feeding, cleaning, shopping, cooking, and transporting oneself. The categories for the logistic regression analysis were Independent in I-ADL and in P-ADL and Dependent in $\geq 1$ activity in $I-A D L$ and in $P-A D L$.

Risk of depression was measured by the Geriatric Depression Scale (GDS) (Brink et al., 1982). A Swedish modified version was used, including 20 items with yes or no responses. Scores from 0-5 suggest that there is No risk of depression, and scores above 5 suggest that there is a Risk of depression (Gottfries, Noltorp, Nørgaard, Holmén \& Högstedt, 1997).

\section{Statistics}

A logistic regression analysis was performed using the backward Wald method. This method includes a model where the variable with the smallest contribution to the model is removed stepwise (Altman, 1991). The dependent variable and the 12 independent variables were included in the analysis. In step 9 the variables with significant impact remained.

\section{Results}

\section{Description of participants}

Among the 198 participants who were categorized as frail, there were 179 participants who completed all of the items included in the logistic regression analysis. The 19 participants who were not included in the final analysis had missing values for one or more of the items (independent variables). Characteristics of the participants included in the final analysis are presented in Table 1.

Table 1. Socioeconomic conditions and life satisfaction for participants included in the logistic regression analysis $(n=179)$.

\begin{tabular}{lc} 
Characteristics & \\
Age (years) & $68-96$ \\
Range & 84 \\
Median & 66 \\
Female, $\%$ & 65 \\
Living alone, \% & 38 \\
Academic education, \% & 88 \\
\hline Good financial situation, \% & 47 \\
Life satisfaction: satisfied, $\%$ & \\
\hline
\end{tabular}


Table 2. Logistic regression predicting likelihood of being satisfied with life.*

\begin{tabular}{|c|c|c|c|c|c|c|c|}
\hline & B & S.E. & Wald & Odds ratio & $\begin{array}{l}95 \% \text { CI } \\
\text { Lower }\end{array}$ & $\begin{array}{l}\text { ds ratio } \\
\text { Upper }\end{array}$ & $\mathbf{P}$ \\
\hline Age & -0.07 & 0.57 & 0.02 & 0.93 & 0.31 & 2.84 & 0.90 \\
\hline Gender & -0.17 & 0.43 & 0.16 & 0.84 & 0.36 & 1.95 & 0.69 \\
\hline Cohabitant/living alone & 0.51 & 0.37 & 1.92 & 1.66 & 0.81 & 3.41 & 0.17 \\
\hline Education & -0.13 & 0.36 & 0.13 & 0.88 & 0.44 & 1.78 & 0.72 \\
\hline Financial situation & 1.26 & 0.62 & 4.09 & 3.53 & 1.04 & 11.95 & 0.04 \\
\hline Contact with children & -0.48 & 0.41 & 1.37 & 0.62 & 0.28 & 1.38 & 0.24 \\
\hline Social contacts & 0,89 & 0.35 & 6.71 & 2.44 & 1.24 & 4.80 & 0.01 \\
\hline Self-rated health & 1.03 & 0.35 & 8.47 & 2.79 & 1.40 & 5.56 & 0.00 \\
\hline Illness & 0.39 & 0.52 & 0.57 & 1.48 & 0.53 & 4.13 & 0.45 \\
\hline Independence in I-ADL & 0.01 & 0.43 & 0.00 & 1.01 & 0.43 & 2.35 & 0.99 \\
\hline Independence in P-ADL & 0.55 & 0.47 & 1.41 & 1.73 & 0.70 & 4.31 & 0.24 \\
\hline Risk of depression & 0.82 & 0.36 & 5.15 & 2.26 & 1.12 & 4.59 & 0.02 \\
\hline
\end{tabular}

*Nagelkerke R squared $=0.24$

\section{Relationships between life satisfaction and socioeco- nomic conditions, social networks, and health-related conditions}

The independent variables and their contributions to the model are presented in Table 2. Four of the independent variables made statistically significant contributions to the model: financial situation (OR 3.53), social contacts (OR 2.44), risk of depression (OR 2.26), and selfreported health (OR 2.79). The Hosmer-Lemeshow test is presented in Table 3. Examination of residuals showed that the model fitted to the data.

\section{Discussion}

The study aimed to examine relationships between frail older people's life satisfaction and their socioeconomic conditions, social networks, and health-related conditions. Logistic regression was performed to assess the impact of 12 independent variables on the likelihood that the participants would report satisfaction with life. Four of the variables made statistically significant contributions to the model: financial situation, social contacts, risk of depression, and self-reported health.

While findings from earlier studies (Berg et al., 2009; Hamarat et al., 2002; Prenda \& Lachman, 2001) addressing the relationship between old age and life satisfaction have appeared ambiguous, this study contributes clarity by analyzing additional circumstances relating to life satisfaction in old age. Because the importance of frailty in the older people's low life satisfaction had previously been underlined by Wilhelmson et al. (2013), our study uniquely focused on this specific subgroup of older people. These findings are important for understanding what conditions impact frail older people's life satisfaction and whether these conditions differ from those of the general elderly population.

The strongest positive impact on life satisfaction in our study was the financial situation. The participants who reported having a good financial situation were about three and a half times more likely to report satisfaction with life than those who did not report good financial situation (OR 3.53). The importance of the financial situation for high life satisfaction of participants of all ages has been reported in earlier studies (Berg et al., 2009; Diener et al., 1999). However, our
Table 3. Hosmer-Lemeshow test.

\begin{tabular}{lccc} 
Step & Chi-square & Df & Sig \\
1 & 5.54 & 8 & 0.70 \\
2 & 5.24 & 8 & 0.73 \\
\hline 3 & 8.22 & 8 & 0.41 \\
4 & 5.16 & 8 & 0.74 \\
\hline 5 & 5.30 & 8 & 0.73 \\
6 & 4.61 & 8 & 0.80 \\
\hline 7 & 4.20 & 8 & 0.84 \\
8 & 2.10 & 7 & 0.95 \\
\hline 9 & 2.12 & 7 & 0.95 \\
\hline
\end{tabular}

results differ from those of another study among frail older people, where no association between financial situation and life satisfaction was found (Abu-Bader et al., 2003).

It appears that self-perception of one's health condition is a stronger correlate of life satisfaction than are medically based measures of health. The medically based measure of health (CIRS-G) in our study did not correlate with life satisfaction. Another study reported a weak relationship between medically based measures of health and life satisfaction among older people (aged $\geq 80$ ) (Berg et al., 2009). This measure of health reflects an objective view of health which differs from self-rated health. Other conditions than illness may influence the selfrated health, which in turn has a greater impact on life satisfaction for frail older people. In our study, self-rated health and risk of depression were related to life satisfaction. These findings coincide with prior studies (Abu-Bader et al., 2003; Hillerås et al., 2001) showing that selfrated health correlates to life satisfaction among frail older people. Similarly, feeling worried has also been significantly related to low life satisfaction (Borg et al., 2008). Our findings that independence in activities of daily living was not significantly related to frail older people's life satisfaction were more surprising, as many prior studies have found a relationship between independence in ADL and life satisfaction (Bowling et al., 1993; Hillerås et al., 2001). Additionally, another study showed that dependence in ADL predicted subjective well-being among people at old-old age (Shmotkin, Shrira, Eyal, Blumstein \& Shorek, 2014). 
The positive impact shown in our study of social networks for frail older people - measured as contacts with others besides children adds further to our understanding of circumstances contributing to high life satisfaction. On the other hand, contact with children had no significant impact in our study. A meta-analysis by Pinquart and Sörensen (Pinquart \& Sörensen, 2000) showed that contact with friends was more strongly related to subjective well-being than having contact with adult children. Further, the quality of social contacts was shown to have a stronger association with subjective well-being than does the quantity of social contacts (Pinquart \& Sörensen, 2000). However, a limitation of our study is that we did not examine the quality of social contacts.

Further, social support has been shown to be associated with depression and self-rated health among a sample of adults up to the age of 75 (Östberg \& Lennartsson, 2007). A positive relationship between social support and life satisfaction has also been found among frail older people, in particular, in two studies by Abu-Bader et al. (2003) and Tomás, Sancho, Gutiérrez, and Galiana (2014).

Living alone or with a partner seemed to have no impact on life satisfaction in our study, and there is a need to address this issue in further research.

The main strength of this study is that it targets frail older people, who are often difficult to include in research projects. Additionally, we used data from two projects that both used the same validated scales and items to measure the dependent and independent variables. However, some methodological limitations need to be discussed in relation to the item on financial situation in the study. Most of the participants $(88 \%)$ answered that they were able to get $12,000 \mathrm{Skr}$ in an emergency situation. This finding could indicate that this amount of money was too small to distinguish between good and poor financial situations. Additionally, the confidence interval on this item is very broad, indicating that this result is somewhat insecure. However, this result may also indicate that the sample was slightly more affluent than people in general.

\section{Conclusions}

This study shows that financial situation, social networks and health-related conditions that are self-rated are important factors for life satisfaction among frail older people. Financial situation had the strongest impact, indicating the importance of structural issues. Health and social care professionals and policy makers should consider this knowledge of life satisfaction in the care and service for frail older people. It is important to promote conditions that benefit life satisfaction for frail older people, such as an encouraging and supportive social environment from contacts in social networks and in society. Additional studies are needed; further exploration in the roles of social networks and socioeconomic conditions, in particular, would offer valuable contributions towards understanding life satisfaction conditions for frail older people.

\section{References}

Abu-Bader, S.H., Rogers, A., \& Barusch, A.S. (2003). Predictors of life satisfaction in frail elderly. Journal of Gerontological Social Work, 38, 3-17.

Altman, D.G. (1991). Practical statistics for medical research. London: Chapman and Hall.

Andrew, M.K., Fisk, J.D., \& Rockwood, K. (2012). Psychological well- being in relation to frailty: a frailty identity crisis? International Psychogeriatrics, 24, 1347-1353.

Berg, A.I., Hassing, L.B., Nilsson, S.E., \& Johansson, B. (2009). As long as I'm in good health. The relationship between medical diagnoses and life satisfaction in the oldest-old. Aging Clinical and Experimental Research, 21, 307-313.

Berg, A.I., Hoffman, L., Hassing, L.B., McClearn, G.E., \& Johansson, B. (2009). What matters, and what matters most, for change in life satisfaction in the oldest-old? A study over 6 years among individuals 80+. Aging \& Mental Health, 13, 191-201.

Borg, T., Berg, P., Fugl-Meyer, K., \& Larsson, S. (2010). Health-related quality of life and life satisfaction in patients following surgically treated pelvic ring fractures. A prospective observational study with two years follow-up. Injury, 41, 400-404.

Borg, C., Fagerström, C., Balducci, C., Burholt, V., Ferring, D., Weber, G., ..., Hallberg, I.R. (2008). Life satisfaction in 6 European countries: the relationship to health, self-esteem, and social and financial resources among people (aged 65-89) with reduced functional capacity. Geriatric Nursing, 29, 48-57.

Bowling, A., Farquhar, M., Grundy, E., \& Formby, J. (1993). Changes in life satisfaction over a two and a half year period among very elderly people living in London. Social Science \& Medicine, 36, 641-655.

Bowling, A., \& Grundy, E. (1997). Activities of daily living: changes in functional ability in three samples of elderly and very elderly people. Age and Ageing, 26, 107-114.

Brink, T.L., Yesavage, J.A., Lum, O., Heersema, P.H., Adey, M., \& Rose, T.L. (1982). Screening Tests for Geriatric Depression. Clinical Gerontologist, 1, 37-43.

Campbell, A., Converse, P.E., \& Rodgers, W.L. (1976). The quality of American life: perceptions, evaluations, and satisfactions. New York: Russell Sage Foundation.

Dahlin-Ivanoff, S., Gosman-Hedström, G., Edberg, A.K., Wilhelmson, K., Eklund, K., Duner, A., ..., Landahl, S. (2010). Elderly persons in the risk zone. Design of a multidimensional, health-promoting, randomised three-armed controlled trial for "prefrail" people of $80+$ years living at home. BMC Geriatrics, 10, 27.

Diener, E., Suh, E.M., Lucas, R.E., \& Smith, H.L. (1999). Subjective well-being: three decades of progress. Psychological Bulletin, 125, 276-302.

Easterlin, R.A. (2003). Explaining happiness. Proceedings of the National Academy of Sciences of the United States of America, 100, 11176-11183.

Engels, J.M., \& Diehr, P. (2003). Imputation of missing longitudinal data: a comparison of methods. Journal of Clinical Epidemiology, $56,968-976$.

Fried, L.P., Ferrucci, L., Darer, J., Williamson, J.D., \& Anderson, G. (2004). Untangling the concepts of disability, frailty, and comorbility: implications for improved targeting and care. The journals of gerontology. Series A, Biological sciences and medical sciences, 59, 255-263.

Fugl-Meyer, A.R., Bränholm, I-B., \& Fugl-Meyer, K.S. (1991). Happiness and domain-specific life satisfaction in adult northern Swedes. Clinical Rehabilitation, 5, 25-33.

Gobbens, R.J., Luijkx, K.G., Wijnen-Sponselee, M.T., \& Schols, J.M. (2010). Toward a conceptual definition of frail community dwelling older people. Nursing Outlook, 58, 76-86.

Gottfries, C., Noltorp, S., Nørgaard, N., Holmén, A., \& Högstedt, B. (1997). Skala identifierar depression bland äldre. Läkartidningen, 94, 1099-1102.

Hamarat, E., Thompson, D., Aysan, F., Steele, D., Matheny, K., \& Simons, C. (2002). Age differences in coping resources and satisfaction with life among middle-aged, young-old, and oldest-old adults. Journal of Genetic Psychology, 163, 360-367. 
Hillerås, P.K., Jorm, A.F., Herlitz, A., \& Winblad, B. (2001). Life satisfaction among the very old: A survey on a cognitively intact sample aged 90 years or above. The International Journal of Aging and Human Development, 52, 71-90.

Horley, J., \& Lavery, J.J. (1995). Subjective well-being and age. Social Indicators Research, 34, 275-282.

Linn, B.S., Linn, M.W., \& Gurel, L. (1968). Cumulative illness rating scale. Journal of the American Geriatrics Society, 16, 622-6.

Majernikova, M., Rosenberger, J., Prihodova, L., Nagyova, I., Roland, R., Groothoff, J.W., \& van Dijk, J.P. (2012). Self-rated health predicts mortality and graft loss after kidney transplantation: a 10-year follow-up study. American Journal of Nephrology, 36, 459-465.

Miller, M.D., Paradis, C.F., Houck, P.R., Mazumdar, S., Stack, J.A., Rifai, A.H., ..., \& Reynolds, C.F. 3rd. (1992). Rating chronic medical illness burden in geropsychiatric practice and research: application of the Cumulative Illness Rating Scale. Psychiatry Research, 41, 237-248.

Mroczek, D.K., \& Spiro, A. (2005). Change in life satisfaction during adulthood: Findings from the veterans affairs normative aging study. Journal of Personality and Social Psychology, 88, 189-202.

Östberg, V., \& Lennartsson, C. (2007). Getting by with a little help: the importance of various types of social support for health problems. Scandinavian Journal of Public Health, 35, 197-204.

Pinquart, M., \& Sörensen, S. (2000). Influences of socioeconomic status, social network, and competence on subjective well-being in later life: a meta-analysis. Psychology and Aging, 15, 187-224.

Prenda, K.M., \& Lachman, M.E. (2001). Planning for the future: a life management strategy for increasing control and life satisfaction in adulthood. Psychology and Aging, 16, 206-216.

Shmotkin, D. (1990). Subjective well-being as a function of age and gender: A multivariate look for differentiated trends. Social Indicators Research, 23, 201-230.
Shmotkin, D., Shrira, A., Eyal, N., Blumstein, T., \& Shorek, A. (2014). The prediction of subjective wellness among the old-old: implications for the "fourth-age" conception. The journals of gerontology. Series B, Psychological sciences and social sciences, 69, 719-729.

Sirgy, M.J. (2012). The psychology of quality of life: hedonic well-being, life satisfaction, and eudaimonia. Dordrecht: Springer Netherlands.

Sonn, U., Grimby, G., \& Svanborg, A. (1996). Activities of daily living studied longitudinally between 70 and 76 years of age. Disability and Rehabilitation, 18, 91-100.

Strawbridge, W.J., Shema, S.J., Balfour, J.L., Higby, H.R., \& Kaplan, G.A. (1998). Antecedents of frailty over three decades in an older cohort. The journals of gerontology. Series B, Psychological sciences and social sciences, 53, S9-S16.

Szebehely, M., \& Trydegård, G.B. (2012). Home care for older people in Sweden: a universal model in transition. Health \& Social Care in the Community, 20, 300-309.

Tomás, J.M., Sancho, P., Gutiérrez, M., \& Galiana, L. (2014). Predicting life satisfaction in the oldest-old: A moderator effects study. Social Indicators Research, 117, 601-13.

Ware, J.E. Jr, \& Sherbourne, C.D. (1992). The MOS 36-item short-form health survey (SF-36). Conceptual framework and item selection. Medical Care, 30, 473-483.

White, J.M. (1992). Marital status and well-being in Canada: an analysis of age group variations. Journal of Family Issues, 13, 390-409.

Wilhelmson, K., Duner, A., Eklund, K., Gosman-Hedström, G., Blomberg, S., Hasson, H., ..., Dahlin-Ivanoff, S. (2011). Continuum of care for frail elderly people: Design of a randomized controlled study of a multi-professional and multidimensional intervention targeting frail elderly people. BMC Geriatrics, 11, 24.

Wilhelmson, K., Fritzell, E., Eklund, K., \& Dahlin-Ivanoff, S. (2013). Life satisfaction and frailty among older adults. Health Psychology Research, 1, e32. 